International Journal of

Environmental Research and

Public Health

ISSN 1660-4601

www.mdpi.com/journal/ijerph

Article

\title{
Different Length (DL) qPCR for Quantification of Cell Killing by UV-induced DNA Damage
}

\section{Knut Rudi $^{1,2}{ }^{*}$, Irina Hagen ${ }^{1}$, Bente Carina Johnsrud ${ }^{1}$, Guro Skjefstad ${ }^{1}$ and Ingun Tryland ${ }^{3}$}

1 Hedmark University College, Lærerskolealleen 1, 2418 Elverum, Norway;

E-Mails: irinahagen@yahoo.no (I.H.); bcjohnsrud@ hotmail.com (B.C.J.);

gskjefstad@hotmail.com (J.S.)

2 NOFIMA Mat, Ås, Norway

3 NIVA Norwegian Water Research Institute, Oslo, Norway; E-Mail: ingun.tryland@niva.no

* Author to whom correspondence should be addressed; E-Mail: knut.rudi@hihm.no;

Tel.: +47-64-97-01-00; Fax: +47-64-97-03-33.

Received: 20 July 2010; in revised form: 3 August 2010 / Accepted: 25 August 2010 /

Published: 31 August 2010

\begin{abstract}
We describe the different length (DL) qPCR method for quantification of UV induced DNA damage in cell killing. The principle of DL qPCR is that DNA damage inhibits PCR. Applications with different lengths can therefore be used to detect different levels of UV-induced DNA damage. The assay was evaluated on three strains of Escherichia coli exposed to varying levels of ultraviolet (UV) radiation. We show that DL qPCR sensitivity and reproducibility are within the range of practical application to detect the effect of UV cell killing.
\end{abstract}

Keywords: viable/dead cells; UV; quantitative PCR

\section{Introduction}

UV-treatment finds wide application for water treatment [1]. Unlike chlorination, UV does not leave chemical traces, and UV is also efficient against parasites [1]. The challenge with UV, however, is that it can be difficult to measure and quantify the decontamination effect. Although the DNA is 
lethally damaged by UV, the cells may physiologically behave as alive with both metabolic activity and intact cell membranes for a long period after UV exposure [2].

The aim of the work presented here was to utilize the property that damaged DNA inhibits PCR [3], and that different lengths of the PCR affect the likelihood of a DNA damage encounter [4,5]. Short PCR amplicons will have a lower likelihood of encounter than long PCR amplicons [6]. We wanted to test if the ratio between long ( 1,500 nt), medium ( $\sim 500 \mathrm{nt})$ and short ( 100 nt) PCRs can be used to measure the degree of DNA damage in a cell. We used Escherichia coli as a model in these investigations. E. coli is both a common water contamination problem and an indicator organism [7]. We present results showing that different length (DL) qPCR can detect lethal UV damage, and that the approach is promising as a tool for screening the effect of UV treatment.

\section{Experimental Section}

We evaluated the laboratory strain $E$. coli DH $5 \alpha$, in addition to two E. coli strains (HIAS strain 1 and 14) isolated from the HIAS sewage treatment plant (Hamar, Norway). The HIAS strains were isolated using growth at $44.5{ }^{\circ} \mathrm{C}$ as a selection criterion, and the strains were confirmed as E. coli using a quantitative PCR test [8].

We used a mercury lamp with a major wavelength output at $254 \mathrm{~nm}$ for the UV treatment. Pure DNA and bacterial cells were UV treated following the same scheme. DNA or cells were added to sterile water to a concentration corresponding to approximately $10^{6}$ cells $/ \mathrm{mL}$. Fifty $\mathrm{mL}$ of the spiked water was added to Petri dishes, and exposed to UV irradiation at room temperature with the doses described in Table 1. Three parallel $1 \mathrm{~mL}$ samples were collected at each time point in black microcentrifuge tubes to prevent photoreactivation. The cells were harvested by centrifugation at 13,000 rpm for $5 \mathrm{~min}$ in a microcentrifuge, while the water containing pure DNA was not treated further. We used Prepman ${ }^{\circledR}$ Ultra for DNA purification with the protocol recommended by the manufacturer (Applied Biosystems, Foster City, CA, USA). Briefly, this protocol involves lysis by boiling and removal of PCR inhibitors by precipitation.

Table 1. Time and UV dose used for each technical replicate in the in the water treatment.

\begin{tabular}{ccc}
\hline Sample \# & Time $(\mathbf{s})$ & UV dose $\left(\mathbf{m W s} / \mathbf{c m}^{2}\right)$ \\
\hline 1 & 0 & not treated \\
2 & 8 & 8 \\
3 & 16 & 16 \\
4 & 30 & $30^{*}$ \\
5 & 40 & $40^{* *}$ \\
6 & 80 & 80 \\
7 & 120 & 120 \\
8 & 200 & 200 \\
9 & 400 & 400 \\
* old recommended dose & $* *$ new recommended dose (www.fhi.no)
\end{tabular}


The DL qPCR amplifications were conducted in a $25 \mu \mathrm{L}$ volume containing $1 \times$ DyNAzyme II Hot Start-buffer, $2 \mu \mathrm{M}$ each of forward and reverse primer, in addition to $1 \mu \mathrm{M}$ Taqman-probe and $1 \mathrm{U}$ DyNAzyme II Hot Start-enzym (Finnzymes, Espoo, Finnland). For pure DNA in water we used $5 \mu \mathrm{L}$ template, while for bacterial cells $1 \mu \mathrm{L}$ template were used. The reactions were run in an Applied Biosystems 7,500 Real-Time PCR System, using the software provided by the manufacturer for data retrieval (Applied Biosystems, Foster City, CA, USA).

The amplification efficiencies were determined by triplicate dilution series from $10^{-1}$ to $10^{-4}$ for each amplicon used using the calibration curve method [9] with the formula; PCR efficiency $=10^{-1 / \text { slope }}-1$. The slope was determined by plotting the log of the dilution as a linear function of the Cqualue using Microsoft Excel (Redmond, WA, USA). The primer sequences, amplification parameters, amplification efficiencies and reproducibility are presented in Table 2. The 16S rRNA gene universal probe described by [10] was used in all the q PCRs.

The amount of qPCR amplifiable DNA in each sample were determined by use of the the respective calibration curves for the amplicons used. The $\mathrm{Cq}$ values were used as input in the formulas, with the amount of amplifiable DNA relative to the standard curves as the output. Finally, for a given amplicon the effect of the UV treatment on amplificable DNA was determined by the difference in log of the estimated amount between two time-point (log amount time 2 minus log amount time 1).

Statistical analyses of differences in qPCR detectable DNA were done by a two-sample T-test for the biological replicates. All statistical tests were done using the TIBCO Spotfire S+ software (TIBCO, Somerville, MA, USA).

Table 2. Properties of the amplicons used.

\begin{tabular}{|c|c|c|c|c|c|c|c|}
\hline \multicolumn{3}{|c|}{ Amplicons } & \multicolumn{3}{|c|}{ Thermocycling } & \multicolumn{2}{|c|}{ Amplification } \\
\hline Name & Primer sequence & Position * & Denaturation & Annealing & Synthesis & Efficiency & $\mathbf{R}^{2}$ \\
\hline Short F & GAAGAAGCACCGGCTAAC & 529 & $95^{\circ} \mathrm{C}-30 \mathrm{~s}$ & $50{ }^{\circ} \mathrm{C}-30 \mathrm{~s}$ & $72{ }^{\circ} \mathrm{C}-30 \mathrm{~s}$ & 0.43 & 1 \\
\hline Short R & GCT TTACGCCCAGTCATTC & 611 & & & & & \\
\hline Medium F & TCCTACGGGAGGCAGCAGT & 375 & $95^{\circ} \mathrm{C}-30 \mathrm{~s}$ & $63^{\circ} \mathrm{C}-30 \mathrm{~s}$ & $72{ }^{\circ} \mathrm{C}-45 s$ & 0.68 & 1 \\
\hline Medium R & GGACTACCAGGGTATCTAATCCTGTT & 841 & & & & & \\
\hline Long F & AAGAGTTTGATCATGGCTCA & 42 & $95^{\circ} \mathrm{C}-30 \mathrm{~s}$ & $55^{\circ} \mathrm{C}-30 \mathrm{~s}$ & $72{ }^{\circ} \mathrm{C}-90 \mathrm{~s}$ & 0.54 & 0.98 \\
\hline Long R & CGGTTACCTTGTTACGACTT & 1546 & & & & & \\
\hline
\end{tabular}

Position relative to 5' of the primers with respect to E. coli $16 \mathrm{~S}$ rRNA.

\section{Results and Discussion}

Despite the relatively low amplification efficiencies the amplicons used have a relatively high quantitative accuracy, as determined by the R2 values for the calibration curves (Table 2). The low and variable amplification efficiencies, however, preclude the direct comparisons of $\mathrm{Cq}$ values. We therefore chose to use the calibration curve transformed data for comparisons of the amount of qPCR detectable DNA. This was done by determining the corresponding dilution from the calibration curve for each $\mathrm{Cq}$ value. Since the dilution series were the same for all amplicons, the estimated amount of DNA can be compared across amplicons. 
UV-treated pure DNA showed a more than two log reduction in detectable DNA compared before UV treatment already after $16 \mathrm{sec}$ exposure for the long DL qPCR. For the medium PCR fragment $40 \mathrm{sec}$ UV exposure led to one log reduction in detectable DNA, while $400 \mathrm{sec}$ was needed for same reduction for the short PCR. For the intact bacterial cells, all three strains showed approximately the same DL Q PCR response to the UV treatment (Figure 1).

Figure 1. Time-series for DL qPCR of for UV treated E. coli DH $5 \alpha$ (A), HIAS strain 1 (B) and HIAS strain 14 (C). The blue curve show the short PCR, the red curve the medium PCR and the green curve the long PCR. Error bars show the standard deviation for three independent analyses of the same UV treated water. The scaling of the y-axis is relative to the respective standard curves.
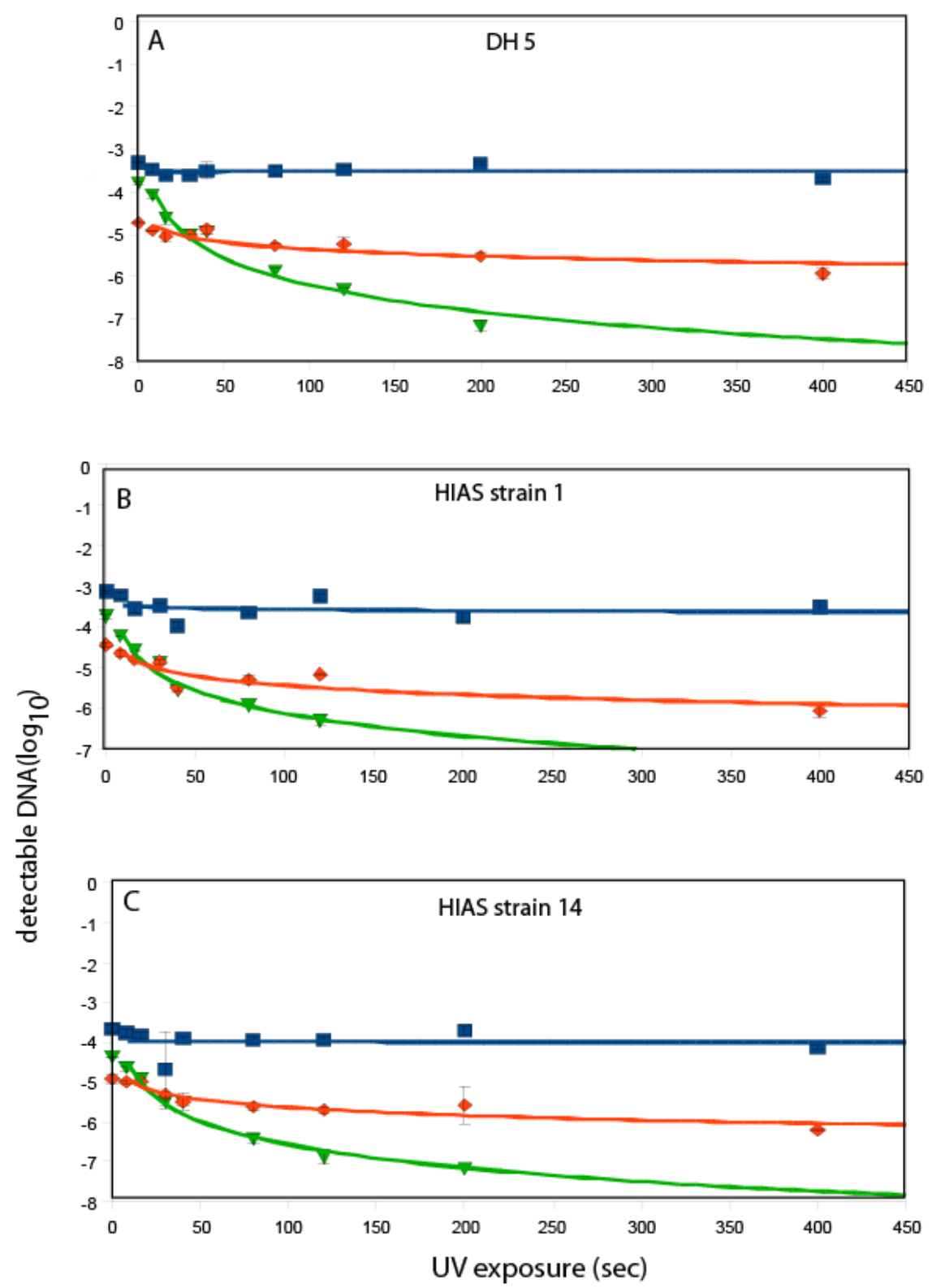
For the long PCR there was a significant reduction in detectable DNA already after $8 \mathrm{sec}(\mathrm{p}<0.05$, $\mathrm{t}$-tests), while for the medium PCR the reduction was not significant until $40 \mathrm{sec}$ ( $\mathrm{p}<0.05$, t-tests). For the short PCR, on the other hand, no significant reduction in PCR signal could be detected even after $400 \mathrm{sec}$ ( $\mathrm{p}>0.05$, t-tests). The plate counts showed a $4.5 \mathrm{log}$ cfu reduction after 8 seconds of UV exposure for the laboratory strain DH $5 \alpha$, while the HIAS strains showed only two log reduction after $8 \mathrm{sec}$. For the other time points analyzed no cfu's were detected. By comparison to the cfu before UV treatment we found that cfu reduction was $>5 \mathrm{log}$ ).

We were able to detect the effect of UV doses as low as $8 \mathrm{mWs} / \mathrm{cm}^{2}$ ( $8 \mathrm{sec}$ exposure in Table 1) using DF qPCR. In Norway the current recommended UV treatment dose for water decontamination is $40 \mathrm{mWs} / \mathrm{cm}^{2}$ (www.fhi.no), so DL qPCR should be within that range of sensitivity for practical application. Although we have only evaluated DF qPCR for E. coli the assay can also be evaluated for other bacterial species since we use conserved 16S rRNA gene primer regions.

Interestingly, although all three strains tested responded similarly with respect to UV-induced DNA, there seemed to be a difference in survival, with the laboratory strain having the lowest survival. Thus, a potential further application of DL qPCR is to optimize UV treatment regimes [1].

\section{Acknowledgements}

We would like to thank Kirsten Frydenlund for valuable laboratory help. We would also like to thank Hedmark Sparebank for financial support.

\section{References and Notes}

1. Hijnen, W.A.; Beerendonk, E.F.; Medema, G.J. Inactivation credit of UV radiation for viruses, bacteria and protozoan (oo)cysts in water: A review. Water Res. 2006, 40, 3-22.

2. Sinha, R.P.; Hader, D.P. UV-induced DNA damage and repair: A review. Photochem. Photobiol. Sci. 2002, 1, 225-236.

3. Sarkar, G.; Sommer, S.S. Parameters affecting susceptibility of PCR contamination to UV inactivation. Bio. Techniques. 1991, 10, 590-594.

4. Swango, K.L.; Hudlow, W.R.; Timken, M.D.; Buoncristiani, M.R. Developmental validation of a multiplex qPCR assay for assessing the quantity and quality of nuclear DNA in forensic samples. Forensic Sci. Int. 2007, 170, 35-45.

5. Niederstatter, H.; Kochl, S.; Grubwieser, P.; Pavlic, M.; Steinlechner, M.; Parson, W. A modular real-time PCR concept for determining the quantity and quality of human nuclear and mitochondrial DNA. Forensic Sci. Int. Genet. 2007, 1, 29-34.

6. Trombert, A.; Irazoqui, H.; Martín, C.; Zalazar, F. Evaluation of UV-C induced changes in Escherichia coli DNA using repetitive extragenic palindromic-polymerase chain reaction (REP-PCR). J. Photochem. Photobiol. B: Biol. 2007, 89, 44-49.

7. Hunter, P.R. Drinking water and diarrhoeal disease due to Escherichia coli. J. Water Health 2003, 1, 65-72.

8. Frahm, E.; Obst, U. Application of the fluorogenic probe technique (TaqMan PCR) to the detection of Enterococcus spp. and Escherichia coli in water samples. J. Microbiol. Method. 2003, 52, 123-131. 
9. Bustin, S.A.; Benes, V.; Garson, J.A.; Hellemans, J.; Huggett, J.; Kubista, M.; Mueller, R.; Nolan, T.; Pfaffl, M.W.; Shipley, G.L.; Vandesompele, J.; Wittwer, C.T. The MIQE guidelines: Minimum information for publication of quantitative real-time PCR experiments. Clin. Chem. 2009, 55, 611-622.

10. Nadkarni, M.A.; Martin, F.E.; Jacques, N.A.; Hunter, N. Determination of bacterial load by real-time PCR using a broad-range (universal) probe and primers set. Microbiology 2002, 148, 257-266.

(C) 2010 by the authors; licensee MDPI, Basel, Switzerland. This article is an open access article distributed under the terms and conditions of the Creative Commons Attribution license (http://creativecommons.org/licenses/by/3.0/). 